\title{
The bowel and beyond: extracolonic findings from CT colonography
}

\author{
Gerard Lambe $^{1}$ (1) $\cdot$ Peter Hughes ${ }^{1} \cdot$ Louise Rice $^{1} \cdot$ Caoimhe McDonnell $^{1} \cdot$ Mark Murphy $^{2} \cdot$ Ciaran Judge $^{3}$. \\ Michael Guiney ${ }^{1}$
}

Received: 10 January 2021 / Accepted: 9 March 2021 / Published online: 24 March 2021

(c) Royal Academy of Medicine in Ireland 2021, corrected publication 2022

\begin{abstract}
CT colonography has emerged as the investigation of choice for suspected colorectal cancer in patients when a colonoscopy in incomplete, is deemed high risk or is declined because of patient preference. Unlike a traditional colonoscopy, it frequently reveals extracolonic as well as colonic findings. Our study aimed to determine the prevalence, characteristics and potential significance of extracolonic findings on CT colonography within our own institution. A retrospective review was performed of 502 patients who underwent CT colonography in our institution between January 1, 2010 and January 4, 2015. Of 502 patients, $60.63 \%$ had at least one extracolonic finding. This was close to other similar-sized studies (Kumar et al. Radiology 236(2):519-526, 2005). However, our rate of E4 findings was significantly higher than that reported in larger studies at 5.3\%(Pooler et al. AJR 206:313-318, 2016). The difference may be explained by our combination of symptomatic/ screening patients or by the age and gender distribution of our population. Our study lends support to the hypothesis that CT colonography may be particularly useful in identifying clinically significant extracolonic findings in symptomatic patients. CT colonography may allow early identification of extracolonic malignancies and life-threatening conditions such as an abdominal aortic aneurysm at a preclinical stage when they are amenable to medical or surgical intervention. However, extracolonic findings may also result in unnecessary investigations for subsequently benign findings.
\end{abstract}

Keywords C-RADS $\cdot$ CT colonography $\cdot$ Extracolonic findings $\cdot$ Screening $\cdot$ Symptomatic

\section{Introduction}

Colonoscopy is the first-line investigation for suspected colorectal cancer. For those patients in whom a colonoscopy is incomplete, is deemed high risk or is declined because of patient preference, CT colonography (CTC) is the next investigation of choice.

CT colonography has several advantages over a traditional colonoscopy. It allows a complete examination of the abdomen and pelvis. It is a relatively safe investigation that is well tolerated by most patients. It was accepted as a screening tool for colorectal cancer by the American Cancer

Gerard Lambe

gerard.lambe@ucdconnect.ie

1 Radiology Department, St. James's Hospital, James's Street, Dublin 8, Ireland

2 Radiology Department, The Mater Misericordiae University Hospital, Eccles Street, Dublin 7, Ireland

3 Gastroenterology Department, St. James's Hospital, James's Street, Dublin 8, Ireland
Society in 2008. Importantly, it also raises the possibility of uncovering extracolonic findings which remain blind to endoscopic examination. Radiologists must report both colonic and extracolonic findings.

A systematic review by Xiong et al. found that $40 \%$ of patients undergoing CT colonography had at least one extracolonic finding. Fourteen percent of all patients had a "significant finding" requiring further investigation [1]. Pooler et al. looked at E4 (potentially significant) findings in a screening population and found that $2.5 \%$ had E4 findings [2].

The aim of our study was to determine the prevalence and characteristics of extracolonic findings from CT colonography within our own institution.

\section{Methods}

A retrospective analysis was conducted of all CT colonography studies performed in our institution from January 1 , 2010 to January 4, 2015 using the picture archiving and 
communication system (PACS). All studies in this period were included in this analysis regardless of the underlying indication for the scan. The total number of patients who underwent $\mathrm{CT}$ colonography during the study period was 502. This comprised 350 females and 152 males with a mean age of 66.63 years.

Patients were administered $20 \mathrm{mg}$ of intravenous hyoscine butylbromide before the scan. They were asked to position themselves in a lateral decubitus position, and a catheter tip was introduced to the rectum. The colon was insufflated with four litres of carbon dioxide to a pressure of 20-25 psi. A topogram was performed before the supine scan to ensure adequate colonic distension. Additional carbon dioxide was administered before the prone scan if tolerated by the patient. No intravenous contrast was administered.

Examinations were performed on a 64-slice Toshiba scanner using a slice collimation of $5 \mathrm{~mm}$, a pitch of 0.8 and a $\mathrm{kVp}$ of 120. Images were networked to a workstation using customised software. All CTs were read by one of two consultant radiologists, each with over 10 years of professional experience.

The formal reports of these studies were examined, and any extracolonic findings were identified. These findings were classified according to the CT colonography reporting and data system [3] (C-RADS) as E0, E1, E2, E3 or E4 (Table 1).

\section{Results}

In total, 303 of 502 patients $(60.36 \%)$ had at least one extracolonic finding. This included 27 patients (5.3\%) who had an E4 finding (Table 2).

The most common benign (E2) findings were renal cyst $(n=54)$, gallbladder calculus $(n=38)$, hiatus hernia $(n=34)$, renal calculus $(n=25)$ and atherosclerotic aorta $(n=24)$ (Table 3$)$. The most common benign but important (E3/4) findings were pulmonary nodule $(n=14)$, renal mass
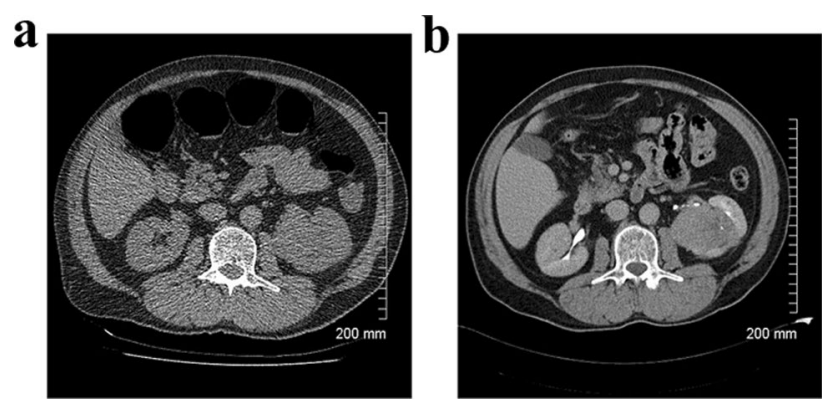

Fig. 1 a Axial non-contrast CT shows a soft tissue mass arising from the interpolar region of the left kidney. b Axial contrast-enhanced CT confirms a $6.4-\mathrm{cm}$ mass. Subsequent histopathology is consistent with a renal cell carcinoma
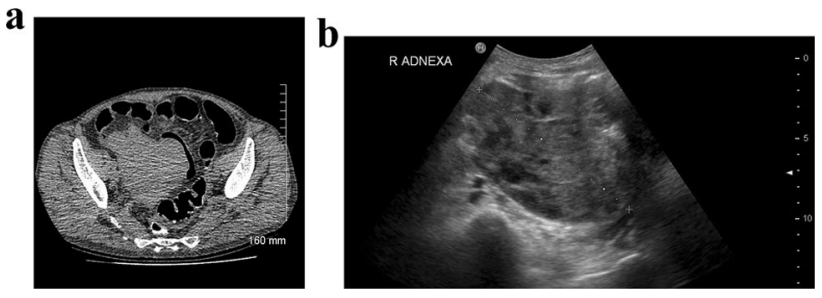

Fig. 2 a Axial non-contrast CT shows a large soft tissue mass in the right pelvis. b Subsequent pelvic ultrasound confirms a mixed solid/ cystic mass arising from the right ovary. Histopathology is consistent with an ovarian carcinoma

$(n=11)$, complex liver lesion $(n=7)$, lymphadenopathy $(n=4)$ and adrenal mass $(n=3)$. Three extracolonic malignancies were incidentally identified on CT colonography during the study period-a renal cell carcinoma (Fig. 1a, b), an ovarian carcinoma (Fig. 2a, b) and a lung carcinoid (Fig. 3), all of which were surgically resected.

\section{Discussion}

Our study aimed to determine the prevalence, characteristics and potential significance of extracolonic findings on CT colonography within our own institution and to compare our experience with that of other centres.

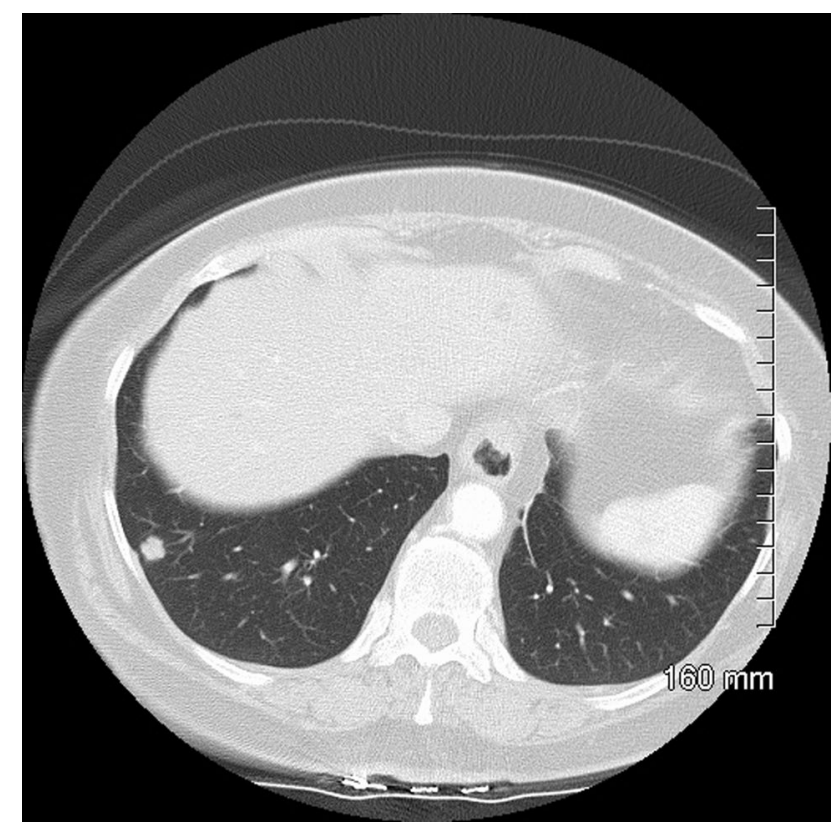

Fig. 3 Axial non-contrast CT shows a 9-mm nodule in the right lower lobe. Subsequent histopathology is consistent with an atypical carcinoid tumour 
Table 1 Summary of CT colonography reporting and data system colorectal and extracolonic classification scores

\begin{tabular}{|c|c|}
\hline Score & Description \\
\hline \multicolumn{2}{|l|}{ Colorectal } \\
\hline $\mathrm{C} 0$, inadequate study & Inadequate preparation; inadequate insufflation \\
\hline $\mathrm{Cl}$, normal colon or benign lesion & $\begin{array}{l}\text { No polyp [greater than or equal to] } 6 \mathrm{~mm} \text {; recommend routine screening with CT colo- } \\
\text { nography or colonoscopy in } 5 \text { years }\end{array}$ \\
\hline $\mathrm{C} 2$, intermediate polyp or indeterminate finding & $\begin{array}{l}\text { Polyps } 6-9 \mathrm{~mm},<3 \text { in number; recommend CT colonography polyp surveillance or } \\
\text { colonoscopy with polypectomy }\end{array}$ \\
\hline C3, polyp, possibly advanced adenoma & $\begin{array}{l}\text { Polyps [greater than or equal to] } 10 \mathrm{~mm} \text {; [greater than or equal to] } 3 \text { polyps, each } 6-9 \\
\text { mm; recommend colonoscopy with polypectomy }\end{array}$ \\
\hline $\mathrm{C} 4$, colorectal mass, like ly malignant & $\begin{array}{l}\text { Lesion compromises bowel lumen, shows extracolonic invasion; recommend surgical } \\
\text { consultation }\end{array}$ \\
\hline \multicolumn{2}{|l|}{ Extracolonic } \\
\hline E0, limited examination & $\begin{array}{l}\text { Compromised by artifact; evaluation of extra colonic tissues severely limited; not used in } \\
\text { practice by our program }\end{array}$ \\
\hline El, normal examination or anatomic variant & No extracolonic abnormalities visible; no workup indicated \\
\hline E2, clinically unimportant finding & $\begin{array}{l}\text { Examples: simple liver or kidney cyst, cholelithiasis without cholecystitis; no workup } \\
\text { indicated }\end{array}$ \\
\hline E3, likely unimportant, incompletely characterised & $\begin{array}{l}\text { Example: minimally complex or homogeneously hyperattenuating kidney cyst; workup } \\
\text { may be indicated; dependent on specific clinical scenario }\end{array}$ \\
\hline E4, potentially important finding & $\begin{array}{l}\text { Examples: solid kidney mass, aortic aneurysm; workup generally indicated, but depend- } \\
\text { ent on specific clinical scenario; communicate to referring physician as per accepted } \\
\text { practice guidelines }\end{array}$ \\
\hline
\end{tabular}

Table is based on data published elsewhere [41]

A retrospective review by Hara et al. first drew attention to extracolonic findings from CT colonography [4]. They found that 30 (11\%) of 264 patients at high risk of colorectal cancer had highly important extracolonic findings. Pickhardt et al. found that extracolonic cancer exceeded colorectal cancer in a retrospective review of 10,286 patients in a CT colonography screening population [5]. However, a 2009 commentary predicted a "deluge" of incidental findings from CT colonographies which would drive up costs, anxiety, morbidity and mortality [6].

The major advantage of CT colonography is the early identification of extracolonic malignancies and lifethreatening conditions such as an abdominal aortic aneurysm at a preclinical stage when they are still amenable to medical or surgical intervention. It is a relatively safe investigation which is well tolerated by the majority of patients.

Table 2 The number of E0, E1, $\mathrm{E} 2, \mathrm{E} 3$ and $\mathrm{E} 4$ findings in our study group

\begin{tabular}{ll}
\hline $\begin{array}{l}\text { C-RADS E } \\
\text { score }\end{array}$ & $\begin{array}{l}\text { Total CT colo- } \\
\text { nography }(n= \\
502)\end{array}$ \\
\hline EO & 5 \\
E1 & 194 \\
E2 & 212 \\
E3 & 61 \\
E4 & 30 \\
\hline
\end{tabular}

One disadvantage of CT colonography is radiation exposure in a situation where the alternative (optical colonoscopy) is radiation-free. Modern CT scanners with a lowdosage protocol can keep doses under $5 \mathrm{mSv}$. However, an increased risk of malignancy seems likely, particularly for older patients and those undergoing multiple scans [7]. There is significant expense associated with further investigations. One study found that the mean cost of working up unexpected findings from CT colonography was approximately equal to the cost of the CT colonography itself [8]. Halligan et al. found that the average cost per patient of working up extracolonic findings was $£ 99 \mathrm{v} £ 5$ for CT colonography $\mathrm{v}$ barium enema, and $£ 153 \mathrm{v} £ 0$ for CT colonography $\mathrm{v}$ colonoscopy [9].

In addition, extracolonic findings may result in "unnecessary" investigations for subsequently benign findings. However, Plumb et al. used a discreet choice experiment in a CT colonography screening population to establish that both patients and healthcare professionals believe that the diagnosis of an extracolonic malignancy from a screening CT colonography outweighs the potential disadvantages of further imaging and invasive investigations brought about by false positive results. For patients, the median tipping point was $99.8 \%$ for radiological follow-up and $10 \%$ for invasive follow-up. The median tipping point for healthcare professionals was $40 \%$ for radiological follow-up and 5\% for invasive follow-up. It appears that the specificity of a CT 
Table 3 The relative number of benign and malignant extracolonic findings are illustrated

\begin{tabular}{|c|c|c|c|}
\hline Benign finding & Number & Malignant finding & Number \\
\hline Renal cyst & 54 & Ovarian carcinoma & 1 \\
\hline Gallbladder calculus & 38 & Renal cell carcinoma & 1 \\
\hline Hiatus hernia & 34 & Lung carcinoid & 1 \\
\hline Renal calculus & 25 & Total & 3 \\
\hline Atherosclerotic aorta & 24 & & \\
\hline Hepatic cyst & 22 & & \\
\hline Abdominal/pelvic hernia & 18 & & \\
\hline Granulomatous disease & 16 & & \\
\hline Pulmonary nodule & 14 & & \\
\hline Abdominal aortic aneursym $<\mathrm{S} \mathrm{cm}$ & 13 & & \\
\hline Emphysema & 12 & & \\
\hline Renal mass & 11 & & \\
\hline Adrenal adenoma/hyperplasia & 10 & & \\
\hline Fatty liver & 8 & & \\
\hline Renal scarring/atrophy & 7 & & \\
\hline Complex liver lesion & 7 & & \\
\hline Vertebral fracture & 7 & & \\
\hline Adnexal cyst & 6 & & \\
\hline Abdominal/pelvic lymphadenopathy & 4 & & \\
\hline Portal HTN/Chronic liver disease & 3 & & \\
\hline Uterine fibroids & 3 & & \\
\hline Pectus excavatum/carinatum & 3 & & \\
\hline Spinal scolioisis & 3 & & \\
\hline Adnexal mass & 3 & & \\
\hline Bronchiectasis & 3 & & \\
\hline Adrenal mass & 3 & & \\
\hline Splenic cyst & 3 & & \\
\hline Prostatomega ly & 2 & & \\
\hline Chronic interstitial lung disease & 2 & & \\
\hline Splenunculus & 2 & & \\
\hline Chronic pancreatitis & 2 & & \\
\hline Pleural plaques & 2 & & \\
\hline Splenomegaly & 2 & & \\
\hline Horseshoe kidney & 2 & & \\
\hline Spondylosis & 2 & & \\
\hline Complex bladder lesion & 2 & & \\
\hline Pulmonary groundglass attenuation & 2 & & \\
\hline Complex pancreatic lesion & 2 & & \\
\hline Angiomyolipoma & 2 & & \\
\hline Peritoneal deposits & 1 & & \\
\hline Obstructing renal calculus & 1 & & \\
\hline Breast mass & 1 & & \\
\hline Gallbladder thickening & 1 & & \\
\hline Groin mass & 1 & & \\
\hline Pancreatic cyst & 1 & & \\
\hline Ectasia of the abdominal aorta & 1 & & \\
\hline Calcified lymph nodes & 1 & & \\
\hline Sacroiliitis & 1 & & \\
\hline Sacral meningocele & 1 & & \\
\hline Absent kidney & 1 & & \\
\hline Pars defect & 1 & & \\
\hline
\end{tabular}


Table 3 (continued)

\begin{tabular}{|c|c|c|c|}
\hline Benign finding & Number & Malignant finding & Number \\
\hline Adrenal haemorrhage & 1 & & \\
\hline Hepatomegaly & 1 & & \\
\hline Dilated common bile duct & 1 & & \\
\hline Bladder calculus & 1 & & \\
\hline IPMN lesion of the pancreas & 1 & & \\
\hline Liver haemangioma & 1 & & \\
\hline Common iliac aneurysm & 1 & & \\
\hline Fusion of L2 and L3 & 1 & & \\
\hline Spondylolisthesis & 1 & & \\
\hline Thoracic aortic aneurysm & 1 & & \\
\hline Total & 400 & & \\
\hline
\end{tabular}

colonography in a screening population is likely to be highly acceptable to both patients and doctors [10].

The reported incidence of extracolonic findings in the literature is variable. The overall incidence in our study was $60.63 \%$. This was close to other similar-sized studies [11]. Smaller studies have reported lower incidences. The incidence was $41 \%$ in a study by Hara et al. [4] and $15 \%$ in a study by Edwards et al. [12]. However, our rate of E4 findings was significantly higher than that reported in the largest study of 7952 screening patients [2].

It was suggested that this may be due to our own combination of symptomatic and screening patients. However, a recent 2019 study of 388 patients found no statistically significant difference in $E$ scores or clinical outcomes of extracolonic findings between symptomatic and screening patients [20]. It is likely that other factors such as the age and gender distribution of our population are at play.

An increased incidence of extracolonic findings from CT colonography is associated with the use of intravenous contrast [13], high-dosage radiation protocols [14], increasing age [15] and female gender [16]. In particular, the predominance of females in our study most likely explains the high number of E3/E4 findings, since other studies have found that up to $25 \%$ of E3 findings are adnexal or uterine lesions [21].

Symptomatic patients with a colonic finding are less likely to have an extracolonic finding, while symptomatic patients without a colonic finding are more likely to have an extracolonic finding investigated [16]. In symptomatic patients, it is thought that up to $10 \%$ of extracolonic findings may account for the patient's symptoms from their initial presentation [17].

The CT colonography reporting and data system establishes a standard approach to the reporting of colonic and extracolonic findings and acts as a guide to management by estimating the clinical significance of these findings. A study of 2277 screening patients found that $46 \%$ had at least one extracolonic finding, but only $11 \%$ were E3/4 [19]. A study of symptomatic patients found double the rate of E3/4 findings [9]. Our own study population was a combination of screening and symptomatic patients, and the rate of E3/4 findings was $18 \%$. This lends support to the conclusion that CT colonography may be particularly useful in symptomatic patients.

Our study identified three extracolonic malignancies from 502 patients. It could be hypothesised that CT colonography accelerated these diagnoses. One prospective, randomised trial of patients with symptoms of colorectal cancer found that extracolonic cancer was indeed diagnosed at twice the expected rate for the general population at 1 year post randomisation to $\mathrm{CT}$ colonography, but time to diagnosis was not reduced compared with patients who underwent a barium enema or colonoscopy [9]. This would suggest that patients who underwent a barium enema or colonoscopy as their initial investigation may have undergone further abdominopelvic imaging as a result of persistent abdominal symptoms not explained by the initial test, ultimately leading to a diagnosis of extracolonic cancer in a similar timeframe to patients who had a CT colonography up front.

It has been suggested that radiographers may have a role in identifying extracolonic findings at the time of the scan and performing further same-day imaging if and when required. However, a Dutch study in 2012 invited eight radiographers to engage in a structured training programme, to triage cases based on the CT colonography reporting and data system and to flag the appropriate scans for a radiologist review. They found that correct identification of E3 findings improved from 52 to $70 \%$ after training, but identification of E4 findings was unchanged at 69\% [18]. As such, radiographers should not be expected to identify all extracolonic findings.

Our study was limited to a single centre. The CT colonography reporting and data system was designed for screening rather than symptomatic investigations, and the absence of a comprehensive classification table means that the $E$ score given is dependent on the subjective opinion of the reporting 
radiologist. Two radiologists report CT colonography studies in our institution, and their personal thresholds for reporting extracolonic findings may vary, particularly for those that are perceived to be low risk.

The National Bowel Screening Programme, Bowel Screen, was rolled out in 2012. While CT colonography studies have largely been deferred in our institution since the start of the COVID-19 pandemic, they have recently been restarted on a regular basis. The resultant backlog is likely to result in greater pressure on CT colonography services at a local and national level.

In summary, our study aimed to assess the prevalence, characteristics and potential significance of extracolonic findings on CT colonography within our own institution. We found a similar rate of extracolonic findings to other similarsized studies [11] but a higher rate of E4 findings than larger studies [2]. Our study lends support to the hypothesis that CT colonography may be particularly useful in identifying clinically significant extracolonic findings in symptomatic patients, and this will bring both opportunities and challenges in the years ahead.

\section{Declarations}

Ethical approval This article does not contain any studies with human participants or animals performed by any of the authors.

Conflict of interest The authors declare that they have no conflict of interest.

\section{References}

1. Xiong $\mathrm{T}$, Richardson M, Woodroffe R et al (2005) Incidental lesions found on CT colonography: their nature and frequency. Br J Radiol 78(925):22-29

2. Pooler BD, Kim DH, Pickhardt PJ (2016) Potentially important extracolonic findings at screening CT colonography: incidence and outcomes data from a clinical screening program. AJR 206:313-318

3. Zalis ME, Barish MA, Choi JR et al (2005) CT colonography reporting and data system: a consensus proposal. Radiology 236(1):3-9

4. Hara AK, Johnson CD, MacCarty RL, Welch TJ (2000) Incidental extracolonic findings at CT colonography. Radiology 215:353-357

5. Pickhardt PJ, Kim DH, Meiners RJ et al (2010) Colorectal and extracolonic cancers detected at screening CT colonography in 10,286 asymptomatic adults. Radiology 255:83-88
6. Berland LL (2009) Incidental extracolonic findings on CT colonography: the impending deluge and its implications. J Am Coll Radiol 6:14-20

7. Albert JM (2013) Radiation risk from CT: implications for cancer screening. Am J Roentgenol 201:W81-W87.AT

8. Xiong T, McEvoy K, Morton DG et al (2006) Resources and costs associated with incidental extracolonic findings from CT colonography: a study in a symptomatic population. Br J Radiol 79:948-961

9. Halligan S, Wooldrage K, Dadswell E et al (2015) SIGGAR investigators, Identification of extra-colonic pathologies by computed tomographic colonography in symptomatic patients. Gastroenterology. https://doi.org/10.1053/j.gastro.2015.03.011

10. Plumb AA, Boone D, Fitzke H et al (2014) Detection of extracolonic pathologic findings with CT colonography: a discrete choice experiment of perceived benefits versus harms. Radiology 273:144-152

11. Yee J, Kumar NN, Godara S et al (2005) Extracolonic abnormalities discovered incidentally at CT colonography in a male population. Radiology 236(2):519-526

12. Edwards JT, Wood CJ, Mendelson RM, Forbes GM (2001) Extracolonic findings at virtual colonoscopy: implications for screening programs. Am J Gastroenterol 96:3009-3012

13. Spreng A, Netzer P, Mattich J et al (2005) Importance of extracolonic findings at IV contrast medium-enhanced CT colonography versus those at non-enhanced CT colonography. Eur Radiol 15:2088-2095

14. van Gelder RE, Venema HW, Serlie IW et al (2002) CT colonography at different radiation dose levels: feasibility of dose reduction. Radiology 224:25-33

15. Park SK, Park DI, Lee SY et al (2009) Extracolonic findings of computed tomographic colonography in Koreans. World J Gastroenterol 15:1487-1492

16. Khan KY, Xiong T, McCafferty I et al (2007) Frequency and impact of extracolonic findings detected at computed tomographic colonography in a symptomatic population. Br J Surg 94:355-361

17. Ng CS, Doyle TC, Courtney HM et al (2004) Extracolonic findings in patients undergoing abdomino-pelvic CT for suspected colorectal carcinoma in the frail and disabled patient. Clin Radiol 59:421-430

18. Boellaard TN, Nio CY, Bossuyt PMM et al (2012) Can radiographers be trained to triage CT colonography for extracolonic findings? Eur Radiol 22(12):2780-2789

19. Veerappan GR, Ally MR, Choi JH et al (2010) Extracolonic findings on CT colonography increases yield of colorectal cancer screening. AJR Am J Roentgenol 195:677-686

20. Taya M, McHargue C, Ricci ZJ et al (2019) Comparison of extracolonic findings and clinical outcomes in a screening and diagnostic CT colonography population. Abdom Radiol (NY) 44(2):429-437. https://doi.org/10.1007/s00261-018-1753-3

21. Pooler BD, Kim DH, Pickhardt PJ (2016) Indeterminate but likely unimportant extracolonic findings at screening CT colonography (C-RADS Category E3): incidence and outcomes data from a clinical screening program. AJR Am J Roentgenol 207(5):996-1001. https://doi.org/10.2214/AJR.16.16275 